\title{
Ending marine pollution
}

\author{
Scientific evidence sheds light on the extent, source and type of litter in the oceans, as well as on the limited efforts \\ to clean it up so far. As we rely on healthy oceans for our future, it's time to act.
}

W ell into 2021, most countries around the world continue to battle with the impacts of the COVID-19 pandemic. On 11-13 June, the G7 leading democracies (Canada, France, Germany, Italy, Japan, United Kingdom and United States, plus the European Union) are set to meet in Cornwall, United Kingdom, to help win the fight against the pandemic and discuss how to build a more prosperous future for all. A lot has been said about the need to shape sound recovery policies centred on health and sustainability and collaborations have emerged over the course of the past year to inform decision makers on what, and how, to innovate in order to bounce forward sustainably. The G7 countries have a unique opportunity to listen to science and lead the efforts of the global community in pursuit of innovative policies that can build a more sustainable development trajectory across the globe.

Against this backdrop, the International Programme on the State of the Ocean (IPSO) virtually convened marine scientists from different countries to work out a plan of action to ensure a sustainable ocean future. The scientists wrote a statement known as 'Seven asks for the G7' to request that priority is given to the protection of the oceans in the pandemic recovery plans that are to be discussed at the summit in Cornwall.

Mounting scientific evidence of the severe impacts of human actions on the ocean environment, and the associated societal and economic implications of those impacts, leaves everyone with no doubt about the risk of inaction. Politicians around the world have to step up efforts now.

One of the seven 'asks' from the IPSO convening is about ocean pollution. Although public awareness of the problem has grown rapidly over the past years, with several reports in the media, policy makers need comprehensive and reliable data about the actual magnitude and nature of the problem in order to intervene. In an article by Morales-Caselles and colleagues in Nature Sustainability, the authors conduct a substantial effort to harmonize worldwide aquatic litter inventories. The harmonized data show that ocean litter globally is dominated by plastics from take-out food, followed by fishing gear - a stark sign of how human activities, and in particular our

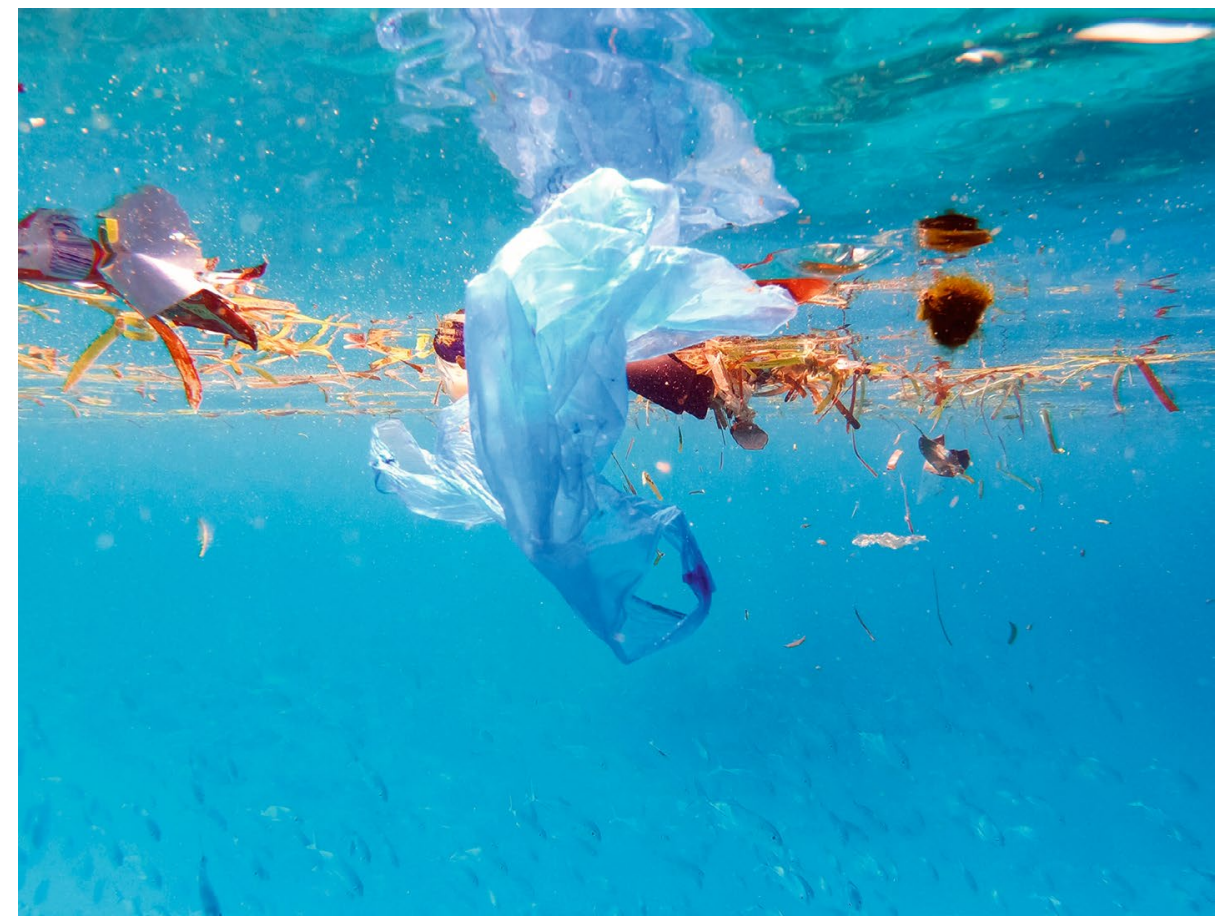

Credit: Ahmed Areef / Alamy Stock Photo

food habits, impact the oceans. The experts are also able to show how litter is trapped in near-shore areas with land-sourced plastic reaching the open ocean mostly as small fragments. In another article by González-Fernández and co-authors, using a unique database of riverine floating macrolitter across Europe, the authors estimate that 307-925 million litter items $-82 \%$ of which is plastic - are transferred from Europe to the ocean annually. They also find that a major portion of the total litter loading is transferred through small rivers, streams and coastal run-off. This result clearly urges countries in Europe to increase efforts to keep rivers pollution-free. Overall, both papers suggest that waste management alone won't be enough consumption habits do play a key role in the fight against ocean litter.

Innovative solutions - to prevent, monitor and clean (PMC) marine litter are necessary to restore healthy oceans and maintain their well-being over time. And again, little is known about how many of these solutions have been developed and implemented, and to what extent they have been effective as information is scattered across platforms and not easily accessible. In a global analysis by Bellou and colleagues, also in Nature Sustainability, the researchers identify 177 PMC solutions and find that 106 of them address monitoring; 33 address prevention (mostly via wastewater treatment); only 30 address cleaning. They also find an inconsistent use of litter size terms across the various developers, which required a harmonization effort to assess the type of litter addressed - results show that 137 of the solutions targeted macrolitter. Overall, only few solutions reached technical readiness and no solution was validated for efficiency and environmental impacts.

Policy makers alongside industry innovators, non-governmental organizations and citizens have a long way to go to address and reverse the trend of ocean pollution. The G7 summit could set the agenda for change - we expect that those influencing players will not shy away from the scientists' call for action on the oceans.

Published online: 10 June 2021

https://doi.org/10.1038/s41893-021-00734-2 